\title{
O ENSINO SUPERIOR NO BRASIL E OS INTERESSES DE CLASSES ENTRE AS DÉCADAS DE 1970 E OS DIAS ATUAIS: QUEM TEVE DIREITO DE ACESSO?
}

\author{
Samara Taveira de OLIVEIRA ${ }^{i}$ \\ José Eudes Baima BEZERRA ${ }^{\text {ii }}$ \\ Maria Margarete Sampaio de Carvalho BRAGA ${ }^{\mathrm{iii}}$ \\ RESUMO
}

Este texto investiga em que medida as políticas educacionais entre os anos 1970 e os dias atuais promoveram o acesso ao Ensino Superior. São consideradas as demandas sociais da classe trabalhadora ou da elite brasileira? As reformas educacionais, promovidas pela Lei $n^{\circ} 5.692 / 1971$ e Lei $n^{\circ}$ 13.415/2017, se encaminham para uma educação emancipada ou atendem a interesses divergentes da classe trabalhadora? Os estudos revelaram que a precarização da educação pública, de nível básico ao superior, intensifica-se no contexto de crise do capital. Os procedimentos metodológicos utilizam o método dialético, com revisão bibliográfica e análise documental. Conclui-se que a educação básica sempre se encaminhou para um processo de dualidade estrutural, direcionando o jovem da classe trabalhadora ao trabalho precoce e, os filhos da elite à Universidade, marcando trajetórias de vida distintas no Brasil.

PALAVRAS-CHAVE: Ensino Superior; Educação Básica; Precarização; Trabalho.

\section{HIGHER EDUCATION IN BRAZIL AND CLASS INTERESTS: BETWEEN THE 1970s AND CURRENT DAYS, WHO HAD RIGHT TO ACCESS?}

\begin{abstract}
This text investigates the extent to which educational policies between the 1970s and the present day have promoted access to College. Do the social demands consider the Brazilian working class or the elite? Are the educational reforms, promoted by Law No. 5,692 / 1971 and Law No. 13,415 / 2017, directed towards an emancipated education or do They serve divergent interests of the working class? Studies have shown that the precariousness of public education, from basic to higher level, intensifies in the context of the capital crisis. The methodological procedures use a dialectical method, with bibliographic review and documentary analysis. It is concluded that basic education has always been directed towards a process of structural duality, directing young people from the working class to early work and, the children of the elite to the University, marking different life trajectories in Brazil.
\end{abstract}

KEYWORDS: University; Basic education; Precariousness; Job.

i Mestrado em Educação pela Universidade Estadual do Ceará, campus FAFIDAM (UECE/FAFIDAM). Professora EBTT do Instituto Federal de Educação, Ciência e Tecnologia (IFCE), campus Cedro. E-mail: samarataveira24@gmail.com - ORCID iD: https://orcid.org/0000-0001-6464-3150.

ii Doutorado em Educação Brasileira pela Universidade Federal do Ceará (UFC). Professor adjunto da Universidade Estadual do Ceará (UECE), atuando no Curso de Licenciatura em Pedagogia e no Programa de Mestrado Acadêmico Intercampi em Educação e Ensino. E-mail: eudes.baima@uece.br ORCID iD: https://orcid.org/0000-0001-9523-3816.

iii Pós-doutorado em Educação pela PUC-SP. Doutorado em Educação pela Universidade Federal de Pernambuco. Professora Adjunta da Universidade Estadual do Ceará (UECE), Centro de Educação. E-mail: margaretesamp@yahoo.com.br - ORCID iD: https://orcid.org/0000-0002-0704-0131. 


\title{
EDUCACIÓN SUPERIOR EN BRASIL E INTERESES DE CLASE: ENTRE LOS AÑOS 1970 $Y$ LOS DÍAS ACTUALES, ¿QUIÉN TENÍA DERECHO A ACCEDER?
}

\begin{abstract}
RESUMEN
Este texto investiga en qué medida las políticas educativas entre los años 1970 y los días actuales promovieron el acceso a la Educación Superior. ¿Son consideradas las demandas sociales de la clase trabajadora o de la élite brasileña? Las reformas educativas, promovidas por la Ley $n^{\circ}$ 5.692/1971 y Ley $n^{\circ}$ 13.415/2017, ¿se encaminan para una educación emancipada o atienden a intereses divergentes de la clase trabajadora? Los estudios revelaron que la precarización de la educación pública, de nivel básico al superior, se intensifica en el contexto de crisis del capital. Los procedimientos metodológicos utilizan método dialéctico, con revisión bibliográfica y análisis documental. Se concluye que la educación básica siempre se encaminó para un proceso de dualidad estructural, direccionando al jovem de la clase trabajadora al trabajo precoz y, los hijos de la élite a la Universidad, marcando trayectorias de vida distintas en el Brasil.
\end{abstract}

PALABRAS CLAVE: Educación Superior; Educación básica; Precariedad; Yo trabajo.

\section{INTRODUÇÃO}

O nosso texto toma como marco histórico inicial a Reforma Capanema, passando pela Reforma educacional dos Militares, Lei no 5.692/1971 e segue numa discussão até os dias atuais, com o dispositivo legal para o Ensino Médio, Lei $\mathrm{n}^{\circ} 1.3415 / 2017$. Em meio a esse percurso, evidencia-se que as reformas na educação pública brasileira sempre estiveram atreladas à promoção de um viés dualista, marcando destinos diferenciados à elite e à classe trabalhadora. A partir de uma perspectiva econômica e de classe, as reformas educacionais se encaminharam no sentido de promover a ascensão social e econômica da classe média e elite no Brasil, por meio da formação em nível superior, em detrimento de uma formação profissionalizante de nível médio, daqueles oriundos de uma classe social desfavorecida. Nesse sentido, as bases de construção da educação brasileira, portanto, do Ensino Médio, são marcadas para alicerçarem essa diferença de classes e seguir num projeto de desenvolvimento de nação que protege um grupo em detrimento do outro. Para tanto, a principal característica da educação brasileira é a dualidade do ensino entre uma formação propedêutica e outra profissionalizante.

Conforme Nascimento (2007) as políticas educacionais do país têm se voltado a reforçar as desigualdades de oportunidades entre jovens de diferentes origens sociais. Essas desigualdades são firmadas a partir da estruturação de uma educação sempre voltada para a 
dualidade de funções sociais que são materializadas nos diferentes currículos escolares. Tendo por base a divisão social do trabalho, a dualidade da educação marca e reafirma a origem social de cada indivíduo que vê o seu percurso profissional sendo traçado ainda na escola. Portanto, "O ensino médio tem sido historicamente, seletivo e vulnerável à desigualdade social". (NASCIMENTO, 2007, p. 78).

No que se refere às políticas de acesso ao Ensino Superior, principalmente público, essa demanda sempre se direcionou à elite brasileira, seja nos governos militares ou no período democrático. No entanto, houve um momento na história do Brasil, que a política de expansão das Universidades públicas atendeu também aos interesses da classe trabalhadora. Esse momento é marcado pela chegada de governos progressistas à Presidência da República, nos mandatos de Luís Inácio da Silva (2003-2010) e Dilma Rousseff (2011-2016).

Nesse período, o acesso da classe trabalhadora ao Ensino Superior foi mais facilitado, via programas sociais, bem como a expansão dessas instituições de ensino com a criação de diversos campi das Universidades Federais nos interiores do país, além da política de criação dos Institutos Federais de Educação. Porém, essa expansão foi obstruída mediante a brusca interrupção do governo Dilma Rousseff, via processo não democrático. Concordamos com Fassoni (2019, ON-LINE) apud Fernandes (2019, ON-LINE) para quem o impeachmant não esteve amparado em nenhuma das hipóteses definidas pelo artigo $n^{\circ} 85$ da Constituição Federal, podendo ser entendido como um rompimento da institucionalidade ou mesmo um golpe no Estado democrático de direito.

Dessa forma, ao assumir a Presidência da República, em 2016, Michel Temer inicia um processo de retirada de direitos sociais da classe trabalhadora, atendendo às demandas do capital financeiro. Com Michel Temer na Presidência, o trabalhador começa a pagar a conta da crise financeira, através de diversos retrocessos decorrentes de cortes no orçamento das pastas da educação e política social, como a Emenda Constitucional (EC) $\mathrm{n}^{\circ}$ 95, de 15 de dezembro de 2016, que "altera o Ato das Disposições Constitucionais Transitórias, para instituir o Novo Regime Fiscal, e dá outras providências", bem como a reforma do Ensino Médio, Lei n ${ }^{\circ}$ 13.415, de 16 de fevereiro de 2017, que inviabiliza em absoluto o acesso da classe menos favorecida ao Ensino Superior, tendo em vista o processo de flexibilização do currículo escolar a partir dos itinerários formativos que reduz os conteúdos escolares e encaminha o ensino profissionalizante à mera prática. 
A deposição do governo Dilma Rousseff, intensificou um processo de crise política, social, econômica, bem como, o combate à diversidade cultural existente no país. O atual governo, Jair Bolsonaro, não tem projetos para alavancar a economia e, muito menos, sair da crise na qual o Brasil se encontra. O país segue numa crise econômica, cujo Produto Interno Bruto (PIB) não chegou a 1\% no primeiro trimestre de 2019 e os índices de desemprego já chegaram a mais de 13 milhões no país. Com isso, segue o aumento do trabalho informal. (BRASIL DE FATO, 2019). Entre outros desastres do governo Jair Bolsonaro, estão os ataques constantes à educação, através do corte de verbas que já chegam a mais de 5,8 bilhões, além de uma guerra ideológica contra os professores. (PINA, 2019). Para fugir de toda essa problemática, o governo Jair Bolsonaro segue no combate a um comunismo e socialismo inexistentes, bem como, na defesa dos valores cristãos para proteger a "família" brasileira.

Os ataques à educação do governo Jair Bolsonaro não o são à toa, fazem parte, também, de uma política de governos de direita que beneficiam a elite e o mercado econômico, em detrimento da classe trabalhadora. Dessa forma, a atual política educacional visa desconstruir qualquer possibilidade, à classe trabalhadora, de ascensão social via educação superior. Pois conforme Nascimento (2007, p. 79),

A economia brasileira, dependente do capitalismo internacional, consolidouse mantendo a tendência de concentração de renda, prestígio social e poder em determinados estratos sociais e regiões do país [...], conservando uma grande parcela da população nacional historicamente excluída de participação na ordem econômica, política e social [...].

Atualmente, a dualidade que marca o acesso ao Ensino Superior no Brasil se encaminha rumo a uma intensificação, a partir dos discursos dos representantes do novo governo, ministros da educação, para os quais o Ensino Superior deve ser direcionado às elites intelectuais do país (VELEZ, apud O GLOBO, 2019, ON-LINE), bem como, a demonstração de Weintraub, no crescimento do ensino superior no segmento privado (MONEY TYMES, 2019, ON-LINE).

Mediante o exposto, esta pesquisa tem como problema compreender a que interesses políticos e classes sociais as políticas públicas para a educação atendem? Assim como, analisar, se as políticas públicas para educação têm contribuído para o acesso ou a negação ao Ensino Superior aos jovens da classe trabalhadora?

Nos objetivos, verificar em que medida as políticas educacionais promoveram o acesso ao Ensino Superior, considerando as demandas sociais da classe trabalhadora ou da elite brasileira. Pretende-se, também, investigar as reformas educacionais na educação básica, 
especificamente se as leis $\mathrm{n}^{\circ} 5.692$, de 11 de agosto de 1971 , e $\mathrm{n}^{\circ} 13.415$, de 16 de fevereiro de 2017, encaminharam ou encaminham no sentido de promover uma educação básica emancipada ou atendem a interesses que não são os mesmos da classe trabalhadora.

A presente pesquisa se fundamenta em uma bibliografia marxista que se centra na discussão dos problemas vivenciados pela educação na atual fase do capitalismo, com fontes de pesquisas mais relevantes acerca do objeto. Portanto, os procedimentos metodológicos serão conduzidos a partir do método dialético como condição necessária para se romper com o modo de pensar a partir da ideologia da classe dominante (FRIGOTTO, 2010). Essa é também uma pesquisa documental, tendo como objeto as leis $\mathrm{n}^{\circ} 5.692 / 1971$ e $\mathrm{n}^{\circ} 13.415 / 2017$. Assim como Farias e Bezerra (2011), concordamos que o documento não se faz neutro, mas sim pertencente a um jogo de forças, representando os interesses de uma determinada classe social. Dessa forma, os referidos dispositivos legais serão analisados como representando os interesses da classe dominante. A partir de Frigotto (2018), Romanelli (2001), Silva (2018), Rodrigues (2008), Nascimento (2007), e outros, bem como alguns portais de notícias que discutem o fenômeno apresentado, buscamos refletir sobre os desdobramentos que cercam a problemática investigada.

\section{O ENSINO SUPERIOR NO BRASIL: CARACTERÍSTICAS E DIFICULDADES DE ACESSO DA CLASSE TRABALHADORA}

Mediante a sanção da primeira Lei de Diretrizes e Bases (LDB) da educação no Brasil, Lei no 4.024, de 20 de dezembro de 1961, que "fixa as Diretrizes e Bases da Educação Nacional”, a nova estruturação do ensino básico permitiu o pleito a todos aqueles concludentes do segundo grau, o que não estava previsto na legislação anterior, referente às leis orgânicas do Ensino, também conhecida como Reforma Capanema, que vigorou dos anos 1940 até a sanção da primeira LDB. No entanto, o atendimento ao pleito não garantiu acesso a todos aqueles que desejavam seguir com os estudos rumo à profissionalização no Ensino Superior.

A Lei n 4.024, de 20 de dezembro de 1961 foi responsável por dar uma nova formatação à estrutura da educação básica no Brasil, organizada em Educação Primária, Ensino Secundário, dividido em Ginasial e Colegial, correspondente ao profissionalizante e, por fim, o Ensino Superior. A partir daí, tanto os estudantes provindos do colegial quanto aqueles oriundos do

Revista e-Curriculum, São Paulo, v. 19, n. 1, p. 368-389, jan./mar. 2021 
ensino profissional poderiam dar continuidade aos seus estudos em nível superior. Dessa forma, a demanda de estudantes que procurou acesso ao Ensino Superior cresceu além da capacidade das Universidades de absorvê-los. Essa situação foi fruto de uma reforma sem investimento financeiro para esse nível educacional.

Em virtude da pressão sofrida pelas Universidades, dois grandes acontecimentos deram um novo rumo à educação brasileira. O primeiro deles se relaciona à aprovação da Lei $n^{\circ} 5.692$, de 11 de agosto de 1971, que "fixa Diretrizes e Bases para o ensino de $1^{\circ}$ e $2^{\circ}$ graus, e dá outras providências", também conhecida como Reforma dos Militares, que reorganizou a educação básica, tornando compulsório o ensino profissionalizante ao ensino de segundo grau. A segunda medida esteve relacionada à expansão do Ensino Superior em instituições privadas (MOURA, 2007).

O cenário político de implantação da referida lei pauta-se numa nova fase do processo de industrialização do país que terá nas camadas populares a sua base de sustentação, no que se refere ao trabalho. Às camadas populares é dada a instrumentalização necessária para compor a demanda dessa nova força de trabalho. Não à toa o governo investiu no ensino profissionalizante, pois um dos motivos foi, também, manter a pressão exercida, pelos recémconcludentes do segundo grau de ingressarem no Ensino Superior, que não dispunha de vagas em número suficiente para atender a parcela desejosa. Portanto, esta deveria se encaminhar ao mercado de trabalho (ROMANELLI, 2001).

Quanto ao Ensino Superior público, o seu acesso continuava sendo feito por aqueles alunos das camadas econômicas mais abastadas, o que nos faz compreender que cursar o Ensino Superior, por muitos anos no Brasil, foi oportunidade tão somente das camadas dominantes. De acordo com Silva (2001, p. 295), como a ampliação de vagas na Universidade pública se deu de forma não significativa, ou seja, sem atender à demanda surgida naquele período, a solução apresentada foi a de que "o ensino privado superior cumpriria uma função complementar, tendo em vista a impossibilidade de o poder público arcar completamente com esse ônus”.

Ainda, conforme Silva (2001), a ideia de que a expansão nesse nível de ensino é, na verdade, a expansão do que havia sido feito, no que se refere à educação básica, sendo, portanto, uma continuidade e ampliação dos negócios do empresariado, referente à educação no Brasil. De acordo com a autora, essa nova atuação do empresariado resulta em duas consequências de ordem política: a proliferação das escolas privadas de Ensino Superior permitindo o acesso de 
vastas camadas da classe média ao ensino universitário cujos cursos ofertados tinham um caráter empresarial, bem diferente dos valores pregados pelas instituições públicas.

Percebemos, portanto, que os governos militares direcionaram a responsabilidade de criação do Ensino Superior às instituições privadas, o que, de todo o modo, coaduna com o próprio regime político, pois, conforme apresentado por Silva (2001), as perspectivas da educação de nível superior privadas voltam-se tão somente para a formação em uma demanda comercial, deixando de lado qualquer direcionamento político-ideológico que se posicionasse contrário ao regime militar, reduzindo as suas responsabilidades no que se refere ao investimento na ampliação de vagas ou, ainda, na construção de novas Universidades. Outra questão tratada por Silva (2001) refere-se à qualidade do ensino nesse setor que, por uma questão de sobrevivência econômica, nivela por baixo as exigências didáticas, facilitando a entrada nos cursos e a ampliação do número de formados.

De acordo com Araújo (2012), a função social das Universidades, conforme o artigo $\mathrm{n}^{\circ}$ 207 da Constituição Federal, deveria ser a de produzir conhecimento de nível superior que possibilite a criação de saberes e tecnologia e a transformação social, a partir da indissociabilidade ensino, pesquisa e extensão no intuito de promover um conhecimento técnico científico voltado aos anseios da população a ser compartilhado nos projetos de extensão. No entanto, poucas Universidades e, somente as públicas, cumprem esse papel. No que se refere à produção de conhecimento nas instituições privadas, segundo Araújo (2012, p. 39), “[...] se tem produzido a lógica de produção capitalista, conclui-se que o conhecimento produzido passa a ser mercadoria, estando disponível somente para quem possa comprá-lo. Nas faculdades particulares essa assertiva é muito clara e palpável [...]”. Nessa lógica, o conhecimento de nível superior é tão somente uma mercadoria sem qualquer finalidade social.

No que se refere à ocupação de vagas na rede púbica de Ensino Superior no Brasil, essa tem ocorrido efetivamente por aqueles alunos oriundos das classes médias, que seguem o seu plano de estudos superiores. Essa constatação nos mostra a reforma do ensino básico na década de 1970, cujo ensino profissionalizante se tornou obrigatório. Essa foi uma medida contenedora de acesso às classes populares ao Ensino Superior a quem recai a responsabilidade de atuar no desenvolvimento da nação, servindo a partir da sua formação profissionalizante.

Conforme Romanelli (2001), com a implantação da indústria de base no Brasil, intensificada no final dos anos 1950, cria-se uma variedade de novos empregos, o que refletiu 
nas políticas educacionais dos anos posteriores. Dessa forma, alteram-se, também, os mecanismos tradicionais de ascensão da classe média, que tradicionalmente se fazia por negócios próprios ou investimentos em poupança, alteram-se conforme a nova economia do país. Desse modo, “as alternativas de ascensão das camadas médias transferem-se para as hierarquias ocupacionais" (ROMANELLI, 2011, p. 205). Percebe-se, então, que a educação torna-se o único meio para a classe média ascender socialmente na conquista de postos de trabalhos superiores.

Vale ressaltar que, conforme Silva (2001), a condição socioeconômica sempre foi primordial como meio de ascensão ao Ensino Superior, ou ainda, aos cursos de maior valorização social. Esse fato ganha destaque quando trata de vagas nas universidades públicas, tendo em vista que os meios de acesso são mais criteriosos, exigindo, portanto, uma formação de nível básico bastante sedimentada, com acervo de grande capital cultural. Com essa constatação, a concepção "mitigada" de Ensino Superior a ser pago, por aqueles que detêm recursos, apresenta-se fragilizada, pois, historicamente as vagas nas universidades públicas vêm sendo ocupadas por alunos de classes econômicas abastadas.

O que se pode constatar, até mesmo estatisticamente, é que a condição sócioeconômica parece representar papel decisivo no ingresso em várias carreiras, principalmente nas universidades públicas mais bem conceituadas.

A superioridade da situação sócio-econômica, se traduz, neste caso, por melhores condições de preparo para o vestibular [...]. Sabe-se que nas carreiras menos competitivas a proporção de ingressantes oriundos de colégios públicos é maior. [...] (SILVA, 2001, p. 297).

Considerando que houve pressão das camadas menos abastadas para, também, terem acesso ao Ensino Superior, algumas concessões foram feitas durante os governos militares. Conforme Cunha (2017), com o acesso de partidos de oposição à assembleia legislativa, nos anos de 1974, duras críticas foram feitas por eles à compulsoriedade e universalidade do ensino profissionalizante. Dessa forma, os governos militares desenvolveram estratégias para atender parte das demandas da oposição. Com isso, já que não se conteve a demanda pela busca às Faculdades e Universidade públicas, a estratégia criada foi ofertá-las em cursos de curta duração, de valor econômico mais baixo.

Nesse sentido, segundo Cunha (2017), os cursos de curta duração, com três anos, que já haviam sido contemplados na reforma universitária, se multiplicaram, mas agora em novo espaço, nas escolas técnicas federais. A questão da inserção de tais cursos em um novo espaço 
foi uma estratégia desenvolvida pelo governo para desviar as massas da universidade e, dessa forma, não prosseguiriam com os estudos na busca dos cursos de longa duração. Essa segregação veio carregada na nova nomenclatura dos cursos de pequena duração, que passaram a ser chamados de Tecnólogo. O currículo desses cursos era intencionalmente diferente dos cursos longos (bacharelado ou licenciaturas), justamente para desestimular o aproveitamento de créditos e, consequente, fazer a complementação da sua formação.

Nesse caminhar, no que se refere à educação básica e o ensino profissionalizante, conforme observamos nas políticas educacionais desde a primeira Lei de Diretrizes e Bases e a Lei de criação dos Institutos Federais, Lei n ${ }^{\circ}$ 11.892, de 29 de dezembro de 2008, "institui a Rede Federal de Educação Profissional, Científica e Tecnológica, cria os Institutos Federais de Educação, Ciência e Tecnologia, e dá outras providências", as reformas educacionais seguem, ainda, na perspectiva de ofertar essa modalidade de ensino às camadas populares como meio de preparação técnica que atenda às demandas do mercado.

Posteriormente, no período democrático, no primeiro governo de Fernando Henrique Cardoso (FHC), através do decreto $n^{\circ} 2.208$ de 17 de abril 1997, "Regulamenta o $§ 2^{\circ}$ do art. 36 e os arts. 39 a 42 da Lei $n^{\circ}$ 9.394, de 20 de dezembro de 1996, que estabelece as diretrizes e bases da educação nacional", o ensino profissionalizante passou a ser ofertado de forma separada do médio propedêutico. A educação dualista torna-se, então, legal, visto que o decreto 2.208/1997 separava oficialmente a obrigatoriedade do ensino médio propedêutico do profissionalizante instituindo as modalidades de curso concomitante e subsequente. Junto com esse decreto, institui-se, também, o Programa de Expansão da Educação Profissional (PROEP), a partir de acordos de empréstimo com o Banco Interamericano de Desenvolvimento (BID). Nesse contexto, o ensino profissionalizante fica ao desejo da iniciativa privada, que passa a direcionar quais as áreas de formação devem ser ofertadas pelo governo federal via Centro Federal de Educação Tecnológica (CEFET). É importante destacar que junto com essa resolução, o número de vagas no ensino médio da rede federal foi reduzido em $50 \%$, pois o projeto neoliberal queria transformar os CEFET'S em escola de perfil apenas profissionalizante (SOUZA, 2012).

Conforme Ferreira (2017), o decreto $\mathrm{n}^{\circ} 2.208$ de 17 de abril 1997, após proibir a junção do ensino propedêutico ao técnico, acentuou a crise de identidade do Ensino Médio. Outro fator relaciona-se à expansão do ensino profissionalizante, via rede privada, em contraponto à oferta 
pública, embora houvesse alta demanda dessa modalidade de ensino, tendo em vista o cenário de desqualificação e desemprego no qual os jovens se encontravam.

Esse programa segue até a posse do governo Luiz Inácio da Silva (Lula), que busca uma solução transitória para garantir a integralidade da educação básica, revogando o decreto 2.208, de 17 de abril de 1997 e sancionando o decreto $\mathrm{n}^{\circ}$ 5.154, de 23 de julho de 2004, que "regulamenta o $\S 2$ - do art. 36 e os arts. 39 a 41 da Lei no 9.394, de 20 de dezembro de 1996, que estabelece as diretrizes e bases da educação nacional, e dá outras providências", no qual o Ensino Médio profissionalizante deve ser ofertado de forma integrada ao propedêutico, embora as modalidades, concomitante e subsequente, sigam existindo.

$\mathrm{Na}$ adoção de suas políticas governamentais, não foram realizadas mudanças estruturais. No entanto, para Oliveira (2009, p. 200), “segundo o relatório da Pesquisa Nacional por Amostra de Domicílios (PNAD) do Instituto Brasileiro de Geografia e Estatística (IBGE), de novembro de 2005, o governo do presidente Lula, estaria fazendo do Brasil um país menos desigual". O seu primeiro mandato, foi marcado por políticas públicas sociais compensatórias as quais permitiram a saída de 8 milhões de brasileiros da extrema pobreza, conforme o PNAD, tais políticas deram sequência à mesma lógica do seu antecessor, FHC. A principal marca do governo Lula foi o Programa Bolsa Família, ampliação e reformulação do programa BolsaEscola criado no governo anterior (OLIVEIRA, 2009).

No que se refere à educação de nível superior, como ponte de acesso a essa modalidade de ensino, a partir de orientações do Banco Mundial (BM), o Exame Nacional de Ensino Médio (ENEM), foi reformulado e dessa forma, passou a integrar os vestibulares de muitas universidades no Brasil através do Sistema de Seleção Unificada (SISU).

De acordo com Espínola e Cavalcante (2014), as decisões tomadas pelo governo Lula acerca do nível Superior de ensino, tiveram como objetivo sanar a crise na qual o mesmo se encontrava. Suas decisões consideraram tanto sanar problemas das instituições públicas quanto privadas. Dentre as ações e estratégias traçadas, apontou-se o aumento da carga horária docente, aumento do número de alunos por turma e ampliação da Educação à Distância $(\mathrm{EaD})$ o que demonstrou quebra de autonomia das Universidades (LEHER, 2003 apud ESPÍNOLA; CAVALCANTE, 2014). Essa política teve sequência também no governo Dilma Rousseff. Nesse sentido, na incapacidade do governo federal alcançar as metas propostas, o uso das Parcerias Público Privadas (PPP) norteou todas as ações para a Educação de ambos os governos do Partido dos Trabalhadores. Para isso, seguiram, então, as orientações da cartilha do BM. 
Segundo Espínola e Cavalcante (2014, p. 11 apud OTRANTO, 2006, p. 02), o documento do BM de 1999 determina que,

[...] o sistema de educação superior dos países periféricos deve contar com poucas universidades de pesquisa, seguidas por universidades de formação profissional de quatro anos, institutos isolados e centros vocacionais e/ou de formação técnica com duração de dois anos.

O BM considera o investimento em formação de pesquisadores um desperdício para os países periféricos. Pelas determinações desse organismo, toda a formação deve ser voltada para uma atuação prática, imediatista conforme as exigências do mercado. Por isso, a ampliação e fortalecimento da Universidade pública não é vista com bons olhos. Dessa forma, os países considerados periféricos não expandem as suas pesquisas e muitos menos a ciência e tecnologia, continuando, então, na dependência dos países desenvolvidos. Desse modo, o governo Lula passa a ampliar as vagas da educação superior a partir da EaD, como sendo a solução mais interessante. Esse modo de fazer Ensino Superior no Brasil, deixa atento o setor mercado privado do ensino que vê aí um nicho de mercado bastante lucrativo (ESPÍNOLA; CAVALCANTE, 2014).

Dessa forma, com a expansão das faculdades particulares, segmento que cresceu vertiginosamente no governo FHC, as PPP do governo Lula, resolvem duas questões importantes ao mesmo tempo: ampliação da oferta de vagas no Ensino Superior e preenchimento das vagas ociosas das faculdades particulares, cujos empresários buscaram uma aliança com o governo Lula para sanar tal déficit. Mediante esse cenário, o Programa Universidade Para Todos (PROUNI) é implantado.

Ao término do governo Lula e posse do governo Dilma Rousseff, as políticas para o Ensino Superior e educação básica seguem praticamente numa continuidade do seu antecessor. Para o Ensino Superior, de acordo com Espínola e Cavalcante (2014, p. 13), Dilma Rousseff amplia os programas já existentes como "aumentando as vagas para o Sistema de Seleção Unificada (Sisu) - o ENEM em 2014 atingiu o recorde de mais de 9 milhões de inscritos”. Estando de certo modo esse nível de ensino organizado, a então presidenta Dilma Rousseff trata de elaborar e implementar um programa que contemple a modalidade profissionalizante, o Programa Nacional de Acesso ao Ensino Técnico e Emprego (PRONATEC).

O PRONATEC foi sancionado através da Lei $\mathrm{n}^{\circ}$ 12.513, de 26 de outubro de 2011, com a finalidade de ampliar a oferta de educação profissional e tecnológica, por meio de programas, 
projetos e ações/subprogramas de assistência técnica e financeira, juntamente com a expansão da Rede Federal de ensino, Institutos Federais, bem como parcerias com o Sistema S (SENAC e SENAI). A sua meta foi capacitar, em nível técnico, 8 (oito) milhões de brasileiros entre 2011 e 2014, atendendo as demandas de diferentes setores da economia. Essa política para o Ensino Médio e a educação profissionalizante segue até a deposição, via golpe parlamentar do governo Dilma Rousseff e posse de Michel Temer, vindo a ser substituído pelo dispositivo legal $\mathrm{n}^{\circ}$ 13.415, de 16 de fevereiro de 2017.

\subsection{Os Rumos da Educação para a Classe Trabalhadora mediante a Lei no 13.415/2017: de Michel Temer a Jair Bolsonaro, como fica a educação pública?}

Quanto à atual política para a educação básica, temos uma série de mudanças em suas bases que se relacionam à completa modificação das Diretrizes Curriculares Nacionais do Ensino Médio (DCNEM’s). Essa reformulação faz parte de uma política pública que atende a interesses que não são os mesmos da classe trabalhadora. O "novo" Ensino Médio representa interesses de setores da economia que vêm a classe trabalhadora como seu objeto de desejo, o trabalha barato, mão de obra desvalorizada e semipreparada a enfrentar um mercado cada vez mais competitivo, mediante um cenário de desemprego estrutural, que encaminha os postos de trabalho formal que ainda existem a um nível máximo de precarização.

De acordo Moura (2007, p. 20), as soluções apresentadas para reformar o Ensino Médio, na verdade, apresentam uma falta de sentido e/ou identidade ao Ensino Médio, pois a mesma "nem confere uma contribuição efetiva para o ingresso digno no mundo do trabalho, nem contribui de forma significativa para o prosseguimento dos estudos de nível superior". Seguindo o posicionamento apresentado por Moura, a atual reforma do Ensino Médio, proposta via Medida Provisória, acarreta mais prejuízos à educação dos jovens que a própria reforma dos anos 1970, tendo em vista que a Lei ${ }^{\circ}$ 13.415, de 16 de fevereiro de 2017 acarreta, em si, a negação dos conteúdos. Ela não é somente uma reforma na estrutura, nem tampouco uma retomada do ensino profissionalizante compulsório. Da forma que está posta, cujo formato se apresenta na escolha dos itinerários formativos pelos estudantes, inviabiliza o acesso destes ao Ensino Superior, tendo em vista que a negação de conteúdos na escola fará falta quando forem realizar as avaliações que poderiam dar acesso à Universidade, seja o ENEM ou vestibulares convencionais, pois tais avaliações seguirão cobrando todas as matérias de ensino 
historicamente presentes no processo de formação básica. De acordo com Frigotto (2016), essa reforma do Ensino Médio

Também retrocede e torna, e de forma pior, a reforma do ensino médio da ditadura militar que postulava a profissionalização compulsória do ensino profissional nesse nível de ensino. Piora porque aquela reforma visava a todos e esta só visa os filhos da classe trabalhadora que estudam na escola pública. Uma reforma que legaliza o apartheid social da educação no Brasil (FRIGOTTO, 2016, p. 331).

Sendo assim, o Estado determina o que a escola irá produzir a partir das demandas sociais do capital. Nesse sentido, torna-se mister compreender que a atual reforma do Ensino Médio é, na verdade, uma "contrarreforma" à luz também da contrarrevolução da classe burguesa que, na busca de se manter no poder, contrapõe-se às parcas conquistas que a classe trabalhadora obteve ao longo dos últimos anos. Dessa forma, com a crise mundial do capital, o sistema não mais suporta os direitos alcançados pelos trabalhadores. Considerando-os gastos, passa a retirá-los, criando o cenário em que a educação deixa de ser investimento social e tornase despesa governamental.

É importante ressaltar que a reforma do Ensino Médio não é um movimento isolado, pois faz parte do pacote de medidas para "conter a crise", junto com a aprovação da Emenda Constitucional $n^{\circ}$ 95, de 15 de dezembro de 2016, que "Altera o Ato das Disposições Constitucionais Transitórias, para instituir o Novo Regime Fiscal, e dá outras providências", a Reforma Trabalhista, Lei no 13.467, de 13 de julho de 2017. Que "altera a Consolidação das Leis do Trabalho (CLT), aprovada pelo Decreto-Lei $n^{\circ} 5.452$, de $1^{\circ}$ de maio de 1943, e as Leis $\mathrm{n}^{\circ}$ 6.019, de 3 de janeiro de 1974, 8.036, de 11 de maio de 1990, e 8.212, de 24 de julho de 1991, a fim de adequar a legislação às novas relações de trabalho" e, ainda a Reforma da Previdência, via Emenda Constitucional n 103, de 12 de novembro de 2019, que "Altera o sistema de previdência social e estabelece regras de transição e disposições transitórias”. Essa reforma, ao contrário do que discursa o governo, irá aprofundar as desigualdades entre os pobres pois, não combate privilégios, somente sacrifica os direitos do trabalhador e da classe média.

Dado o exposto, retomamos a Silva (2001) e Romanelli (2011) sobre o acesso da classe trabalhadora ao Ensino Superior. Percebemos que este vem, tão somente, acompanhado de uma política de contenção dos anseios das massas a tal nível de ensino, ou ainda, um encaminhamento de uma formação complementar àquela de nível básico, que siga no modelo 
de atendimento de questões mercadológicas emergentes, conforme as exigências da economia para aquele período.

Considerando que o governo Michel Temer toma posse da Presidência com o intuito de atender, de forma mais eficaz, às demandas de mercado neoliberal, o mesmo é responsável pelas atuais reformas, nesse período de crise econômica no país, as quais atingem diretamente a classe trabalhadora. Nesse sentido, numa política que intensifica a negação de direitos sociais, o atual governo, Jair Bolsonaro, por meio dos seus dois ministros da educação, apresenta a sua perspectiva para o acesso ao Ensino Superior pela classe trabalhadora.

O primeiro ministro da educação, Ricardo Vélez Rodríguez, retoma a proposta da educação em nível superior para as elites intelectuais e ensino profissionalizante para a classe trabalhadora, reformas que ocorreram nos governos militares dos anos 1970, o mesmo defende a ideia de Ensino Superior para as elites condutoras do país. Conforme O Globo (2019, ONLINE)

Vélez Rodríguez também rechaçou o conceito de universidade para todos, afirmando que elas "devem ficar reservadas para uma elite intelectual", e afirmou que investirá em cursos técnicos como maneira de inserir os jovens mais rapidamente no mercado de trabalho, evitando o que considera desperdício de tempo na faculdade. Como exemplo, citou um estudante de Direito que se torna motorista de Uber: "Esse cidadão poderia ter evitado perder seis anos estudando legislação".

Nessa mesma entrevista, o secretário do Ensino Superior, Mauro Rabelo, afirmou que iria rever o Financiamento Estudantil (FIES) no intuito de seguir com os cortes já iniciados no governo Michel Temer. Embora consideremos que os recursos públicos devam se encaminhar à educação pública, gratuita e de qualidade nas universidades públicas, percebemos no discurso do ministro e seu secretário uma intenção bem longe dessa. O que se percebe é o aprofundamento do fosso educacional já existente entre elite e classe trabalhadora.

Para o então ministro da educação, Weintraub, que tão logo assumiu a pasta do MEC, mediante a saída de Velez, sob a alegação de que as Universidades praticavam "balbúrdia” e descumpriam as suas funções educacionais e sociais, o mesmo anunciou um corte de 30\%, chamando-o de "contingenciamento", nos recursos orçamentários para as instituições federais de ensino: as Universidades Federais, os Institutos Federais (IF's), os Centros Federais de Educação Tecnológica (CEFET's) e o Colégio Pedro II. Conforme discurso em palestra proferida no $12^{\circ}$ Congresso Brasileiro da Educação Superior Particular, Weintraub mostrou-se 
bastante interessado no crescimento desse segmento no setor privado. A fala de Weintraub repercutiu positivamente no crescimento das ações de alguns grupos privados de educação superior no país como o Kroton e a Estácio. Para Weintraub, em entrevista ao Portal Exame (2019, ON-LINE),

Existe espaço para instituições federais e existe para as estaduais, mas, olhando para a perspectiva do Brasil - e o crescimento vai acontecer -, é muito claro que não há condição de o atual estado de contas do setor público nutrir a atual estrutura educacional estatal para atender a demanda que vai acontecer.

O discurso de ambos representa os projetos do atual governo para a educação da classe trabalhadora. Carregam em si um posicionamento das elites dirigentes desse país num esforço de seguir com uma política excludente, negando ao jovem dessa classe acesso à educação e, portanto, a possibilidade de ascensão social. Essa proposta visa manter os jovens da classe menos favorecida sob o domínio das elites, seguindo como um expressivo contingente de mão de obra de reserva ao mercado, dado que coaduna com a própria reforma trabalhista.

Embora tais pronunciamentos de ambos os ministros da Educação pareçam deixar perplexos alguns dos leitores que pensam o mundo numa perspectiva crítica, essas falas vêm tão somente reafirmar aquilo que esteve posto com a reforma do Ensino Médio, pois, a partir da sua implantação, será quase impossível aos jovens da classe trabalhadora ter acesso ao Ensino Superior, pelo menos em se tratando da educação pública e gratuita. Essa de fato, servirá às elites intelectuais do país. Portanto, para o jovem da classe trabalhadora, o acesso ao Ensino Superior se dará tão somente através da iniciativa privada, em cursos cuja formação terá uma qualidade bem comprometida, dada as expansões de instituições que ofertam cursos baratos e cujas aulas correm somente aos finais de semana ou ainda os cursos à distância, os quais crescem vertiginosamente no Brasil desde o governo Lula. Sendo assim, essa formação terá a única finalidade de manter tais grupos no mercado.

Conforme Frigotto (2016), o que compreendemos até então é que a proposição da reforma no Ensino Médio brasileiro segue uma transformação de âmbito mundial para atender ao grande capital. De acordo com Ferreira (2017), no século XX, a expansão do Ensino Médio, em todo o mundo, se faz a partir de políticas educacionais que ajustam o seu projeto político pedagógico aos preceitos da Teoria do Capital Humano. Sendo assim, a escola tem se tornado improdutiva para servir à produção do capital. O ensino médio ficou restrito às elites e, quando 
tem se expandido é para atender as exigências do capital, da formação de mão de obra do setor produtivo.

\subsection{O Acesso ao Ensino Superior: chegou a vez da classe trabalhadora, será?}

Conforme o exposto, tendo como recorte histórico os anos 1970 aos dias atuais, percebemos que o Ensino Superior no Brasil é um privilégio social das camadas mais abastadas da população, principalmente os cursos chamados de longa duração. À elite, foi facilitado o acesso a esse nível de ensino em detrimento das camadas populares, que tiveram que se contentar com o Ensino Médio profissionalizante e uma possível inserção no mercado de trabalho. Quando pensado o acesso ao Ensino Superior, por parcela dessa camada, foi como medida de contenção dos seus anseios, portanto, ofertado a eles os cursos mais curtos, na modalidade Tecnólogo e em espaços diferentes das Universidades, para que os mesmos não ansiassem uma formação mais ampliada.

O processo de democratização da classe trabalhadora à Universidade somente se deu no período histórico que corresponde aos mandatos dos governos Lula (2003 - 2011) e Dilma Rousseff (2011 - 2016). Embora, nesse período, não tenha havido as reformas estruturais necessárias que possibilitassem um real processo de democratização e acesso à educação, foi durante o mandato desses presidentes que ocorreu o maior acesso da classe trabalhadora ao Ensino Superior. Isso se deu em virtude de algumas políticas e programas sociais que possibilitaram o acesso dos mais pobres à Universidade.

Dentre os programas, destacamos a expansão e construção de onze novas Universidades Federais nos interiores dos Estados brasileiros, a reforma das instituições já existentes, a criação de novas vagas para docentes e técnicos administrativos nas Universidades, a implantação da política de cotas, a criação do Programa Universidade Para Todos (ProUni), ampliação do crédito universitário, através do Fundo de Financiamento ao Estudante de Nível Superior (FIES) e a expansão das escolas federais, com a criação dos Institutos Federais de ensino, as quais atuam tanto na educação básica (Ensino Médio profissionalizante), quanto no nível Superior (graduações e pós-graduações) (RODRIGUES; ALMEIDA, 2008).

Quanto à política de cotas, conforme Batista (2018, n.p) "Desde o início do século XXI têm se multiplicado as ações públicas em prol do acesso à Educação Superior para grupos sociais que, ao longo da história da educação brasileira, foram alijados desse nível de ensino". Ainda segundo Batista (2018) essa tal expansão parte do próprio reconhecimento social de que 
há um déficit educacional no que se refere ao cumprimento dos preceitos jurídicos quanto o direito de acesso à educação, conforme prega a Constituição Federal de 1988 e a Lei de Diretrizes e Bases da Educação Nacional (LDBEN), Lei n 9394, de 20 de dezembro de 1996, que "Estabelece as diretrizes e bases da educação nacional".

Esses preceitos se referem tanto ao acesso e permanência quanto à baixa qualidade da educação básica que implicam também no acesso ao Ensino Superior público por parte das camadas mais pobres da população que estudaram em escolas públicas, estudantes de escolas públicas autodeclarados negros e ainda, para indígenas; grupos sociais, historicamente, excluídos do acesso à Educação Superior. Dessa forma, a política de cotas se faz necessária no sentido de buscar uma equalização social, através de políticas compensatórias que atendam às populações historicamente excluídas do acesso às políticas sociais, como o acesso à educação em todos os níveis. Para Batista (2018, n.p),

[...] as políticas públicas de ação afirmativa têm beneficiado cidadãos de grupos discriminados com explícita exclusão socioeconômica e cultural tanto no passado quanto no presente. No caso das cotas para a Educação Superior reserva de vagas étnico-racial, socioeconômica e por origem escolar (escola pública) em Instituições de Ensino Superior (IES) públicas.

Conforme Nunes (2018), a política de cotas é responsável pela ampliação do acesso de pretos e pardos às universidades públicas nos últimos dez anos, marco da inserção da política de cotas raciais. Ainda conforme Nunes (2018, p. 05), de acordo com uma pesquisa da Associação Nacional dos Dirigentes das Instituições Federais de Ensino Superior (Andifes), “o número de alunos pretos e pardos já representavam, há três anos, 47,5\% do total de estudantes das universidades federais do Brasil". No entanto, embora se constituam em maioria da população, não o são ainda nas Universidades públicas. Esse aumento de jovens da classe trabalhadora, nas Universidades públicas, ainda provoca reações negativas por parte de uma camada da sociedade brasileira, classe média, que nos últimos anos veio mostrando o seu descontentamento e desconforto em ter que dividir o "seu" espaço historicamente ocupado com as camadas mais pobres.

Para o caso de outros programas, como o ProUni, há muitas críticas em virtude da sua relação direta em dar sustentação às instituições particulares já existentes. Conforme Rodrigues e Almeida (2008), o Programa, embora surja com um discurso de justiça social, vem a encobrir a pressão das associações que representavam as instituições privadas, descontentes com o 
excedente de vagas ociosas. Embora não neguemos essa primeira intenção, ainda assim, após dez anos de sua criação, esse programa foi responsável por oportunizar o acesso de 1,6 milhão de jovens de baixa renda ao Ensino Superior. Muitos deles foram os primeiros de suas famílias a terem acesso a uma faculdade. Frisamos, aqui, que defendemos o investimento de recursos públicos em instituições públicas, entretanto, não negamos os benefícios à classe trabalhadora advindos desse programa.

Para finalizar essa discussão, retomamos a fala do ex-ministro da educação, Ricardo Vélez, o qual se contrapôs a todas as conquistas sociais, dos trabalhadores advindas do acesso ao Ensino Superior. Ao declarar que a Universidade é para "elites pensantes", ele expõe o posicionamento da elite burguesa que vê a classe trabalhadora tão somente como trabalhadora braçal e, portanto, que deve se contentar com subempregos para os quais não precisa de um conhecimento especializado.

O discurso de Ricardo Vélez externa o pensamento da elite brasileira enraizado no período escravocrata. Os últimos acontecimentos políticos do Brasil que se iniciaram com o segundo mandato da presidenta Dilma Rousseff, a sua deposição do cargo, a partir de um golpe parlamentar que seguiram no desmonte do Estado brasileiro e um conflito de polarização política intenso entre os que defendem o Estado democrático de direito e aqueles que defendem os seus interesses de classe. Dessa forma, caminharemos a um processo intenso de negação de direitos e educação ao trabalhador, com o apoio da classe média e elite dominante brasileira. Esse processo foi retomado com grande força no governo Michel Temer, através da sua política de austeridade.

Quanto ao acesso da classe trabalhadora ao Ensino Superior, certamente será inviabilizado tão $\operatorname{logo}$ ocorra à implantação da Lei $\mathrm{n}^{\circ} 13.415$, de 16 de fevereiro de 2017. Portanto, a fala proferida pelo ex-ministro da educação, se faz coerente com a política de um governo liberal na perspectiva de uma direita conservadora, que negando e retirando conquistas sociais dos trabalhadores, cria uma volumosa força de trabalho de reserva para atender tão somente aos interesses de mercado. Interesses esses que também são de organismos externos os quais constroem as políticas para os países mais pobres, a exemplo do Banco Mundial e o Fundo Monetário Internacional. Assim, vemos mais uma vez um processo de desconstrução de políticas sociais para atender aos interesses do capital e, dessa forma, desrespeitar os preceitos da Constituição Cidadã que reafirma educação pública, universal e de qualidade como dever, primeiro do Estado e, depois, da família. 


\section{CONCLUSÕES}

Conforme o exposto foi possível perceber que a educação básica, portanto, sempre foi estruturada de forma dualista, de modo a manter a ordem social onde aos filhos da elite, o caminho escolar sempre fora trilhado para seguir no Ensino Superior, já os filhos da classe trabalhadora, têm seus destinos decididos a partir da educação profissionalizante, na qual seguirão atendendo aos anseios de mão de obra do mercado. Dessa forma, a Lei $\mathrm{n}^{\circ} 5.692$, de 11 de agosto de 1971, não promoveu o acesso da classe trabalhadora ao Ensino Superior, pelo contrário, criou mecanismos para contê-lo com a formação básica e encaminhá-lo ao mercado de trabalho após conclusão dessa etapa educacional. No que se refere à oferta dos cursos superiores na modalidade Tecnólogo, a mesma lógica se manteve, formação de um perfil mais especializado ao mundo do trabalho e carreiras menos promissoras. Quanto à Lei $\mathrm{n}^{\circ} 13.415$, de 16 de fevereiro de 2017, essa certamente irá dificultar e, possivelmente, impossibilitar a qualquer jovem da classe trabalhadora o acesso ao Ensino Superior, pois, a mesma reduz o currículo escolar a um mínimo de conhecimento, que também não dá formação com qualidade para o mundo do trabalho. O jovem formado pelo "novo" Ensino Médio terá o seu capital cultural escolar negado, preparando-se, assim, tão somente para desenvolver atividades diversas, sem conhecimento amplo de algo, no precário e atual mundo do trabalho.

Percebemos, com isso, que as reformas na educação básica, seja através da Lei n5.692, de 11 de agosto de 1971 ou Lei ${ }^{\circ} 13.415$, de 16 de fevereiro de 2017, embora bastante diferentes em seus dispositivos, carregam, em si, a mesma finalidade, qual seja impedir a classe trabalhadora de acessar o nível superior de ensino e, portanto, formar mão de obra semiespecializada, ou não, como reserva de mercado. Percebemos, portanto, que a atual reforma do Ensino Médio está atrelada, também, à reforma trabalhista, bem como, a EC n 95 de 15 de dezembro 2016.

No que se refere ao Ensino Superior no Brasil, desde a sua política de expansão, nos anos 1970, é direcionado à classe média. No período especificado, a Universidade torna-se mecanismo de ascensão social para as classes mais abastadas, em virtude da nova estrutura econômica do país, iniciada com o processo de industrialização. Nesse período, também, percebemos que, o ensino profissionalizante torna-se compulsório à classe trabalhadora, pois além da necessidade de formação de mão de obra para atender às novas demandas de mercado do país, é uma medida contendedora desses jovens concludentes da educação básica, pois, já 
que o governo não investia na ampliação de novas vagas na Universidade, foi preciso criar um mecanismo de contenção das massas à educação básica, portanto, um desvio de fluxo dessa classe a outra atividade, que foi o ensino profissionalizante. Dessa forma, fica muito claro que a Universidade no Brasil não foi construída para atender às demandas da classe trabalhadora, mas, sim, das elites condutoras do país.

Concluímos, então, que a educação superior no Brasil quase sempre foi direcionada às elites e, por um curto período de tempo, num processo de resistência dos governos progressistas, passaram a ser, também, de acesso da classe trabalhadora. Nesse período, foi possível, ver representantes da diversidade da classe trabalhadora frequentando a Universidade pública, bem como, as faculdades particulares. O que promoveu também o acesso desses sujeitos a bens materiais e culturais que sempre foram de domínio da elite brasileira.

Portanto, conforme o que foi apresentado mostra-se que o acesso à Universidade pela classe trabalhadora, se faz necessário como processo de emancipação humana e social. Somente por intermédio desse nível de ensino, é possível ao trabalhador conquistar postos de trabalho que tenham uma valorização social, sendo respeitado por todos, possibilitando-lhes uma vida digna. Acreditamos nessa perspectiva, dado a formação da educação básica que ainda não consegue promover essa emancipação. Dessa forma, somente o acesso ao Ensino Superior dará ao sujeito a oportunidade de superar as suas condições de classe, a qual ocorrerá através do acesso a um trabalho digno que não seja de exploração da sua força bem como, a bens culturais diversos que ainda são de domínio da elite desse país.

\section{REFERÊNCIAS}

BATISTA, Neusa Chaves. Cotas para o acesso de egressos de escolas públicas na Educação Superior. Pro-Posição. Campinas, v. 29, n 3, p. 41-65, set./dez., 2018. Disponível em: http://www.scielo.br/scielo.php?script=sci_arttext\&pid=S010373072018000300041\&lang=pt. Acesso em: 25 jun. 2018.

BRASIL DE FATO. Estagnação e ausência de política de emprego fazem informalidade bater recorde. São Paulo, 30 de ago. de 2019. Geral. Disponível em: https://www.brasildefato.com.br/2019/08/30/estagnacao-e-ausencia-de-politica-de-empregofazem-informalidade-bater-recorde/. Acesso em: 15 jun. 2019.

CUNHA, Luiz Antônio. Ensino Médio: atalho para o passado. Educ. Soci., São Paulo, v. 38, nº 139, p. 373-384, abr.-jun., 2017. Acesso em: http://www.scielo.br/scielo.php?pid=S010173302017000200373\&script=sci_abstract\&tlng=pt. Acesso em: 12 jun. 2018. 
ESPÍNOLA, André Felipe de Albuquerque; CAVALCANTE, Rita de Cássia. Políticas Públicas da Educação no Período Luiz Inácio Lula da Silva e Dilma Rousseff (2003-2014). In: SEMANA DE HUMANIDADES, VI., 2014. Guarabira, PB... Anais eletrônicos: UEPB, 2014. Disponível em:

https://www.academia.edu/16702042/Pol\%C3\%ADticas_P\%C3\%BAblicas_de_Educa\%C3\% A7\%C3\%A3o_no_Governo_Dilma_e_Lula. Acesso em: 18 jun. 2019.

EXAME. Ministro da Educação diz que ensino superior particular será fortalecido. São Paulo, 07 de jun. de 2019. Educação. Disponível em: https://exame.abril.com.br/brasil/ministro-da-educacao-diz-que-ensino-superior-particularsera-fortalecido/. Acesso em: 20 jun. 2019.

FARIAS, Isabel Maria Sabino de; BEZERRA, José Eudes Baima. Do Documento ao Documento: recompondo o seu lugar histórico. In: THERRIEN, Silvia Maria Nóbrega; FARIAS, Isabel Maria Sabino de; NUNES, João Batista Carvalho (Orgs.). Pesquisa Científica para Iniciantes: caminhando no labirinto. Fortaleza: EdUECE, 2011. p. 43-53.

FERNANDES, Leonardo. Especial: Aniversário do Golpe de Dilma Rousseff. Brasil de Fato. São Paulo, 17 de abr. de 2019. Política. Disponível em: https://www.brasildefato.com.br/2019/04/17/ha-tres-anos-eduardo-cunha-comandava-oinicio-do-fim-do-governo-dilma/. Acesso em: 14 set. 2019.

FERREIRA, Eliza Bartolozzi. A Contrarreforma do Ensino Médio no Contexto da Nova Ordem e Progresso. Educ. Soc., Campinas, v. 38, nº 139, p. 293-308, abr.-jun., 2017. Disponível em: https://www.scielo.br/scielo.php?pid=S010173302017000200293\&script=sci_abstract\&tlng=pt. Acesso em: 15 jul. 2019.

FERREIRA, Eliza Bartolozzi; SILVA, Mônica Ribeiro da. Centralidade do Ensino Médio no Contexto da "Nova" Ordem e Progresso. Educ. Soc., Campinas, v. 38, no 139, p. 287-292, abr./jun., 2017. Disponível em:

http://www.scielo.br/scielo.php?script=sci_arttext\&pid=S010173302017000200287\&lng=pt\&nrm=iso. Acesso em: 14 jul. 2019.

FRIGOTTO, Gaudêncio. O Enfoque da Dialética na Pesquisa Educacional. In: FAZENDA. Ivani (Org.) Metodologia da Pesquisa Educacional. 12. ed. São Paulo: Cortez, 2010. p. 77100.

FRIGOTTO, Gaudêncio. Reformas do Ensino Médio do (Des) governo de turno: decreta-se uma escola pra os ricos e outra para os pobres. Movimento-Revista De educação, Rio de Janeiro, ano 3, n5, p. 329-332, set., 2016. Disponível em: http://www.revistamovimento.uff.br/index.php/revistamovimento/article/view/326/327. Acesso em: 18 ago. 2019.

MOURA, Dante Henrique. Educação Básica e Educação Profissional e Tecnológica: dualidade histórica e perspectivas de integração. Holos, ano 23, vol. 2, 2007. Disponível em: http://www2.ifrn.edu.br/ojs/index.php/HOLOS/article/view/11. Acesso em: 20 ago. 2019. 
NASCIMENTO, Manuel Nelito M. Ensino Médio no Brasil: determinações históricas. Publ. UEPG Ci. Hum., Ci. Soc. Apl., Ling., Letras e Artes, Ponta Grossa, v.15, n 1, 77-87, jun. 2007. Disponível em:

https://www.revistas2.uepg.br/index.php/humanas/article/view/594/581. Acesso em: 04 ago. 2019.

NUNES, Aline. Triplica o número de cotistas nas Federais. Gazeta Online. São Paulo 16 de fev. de 2018. Notícias. Disponível em:

https://www.gazetaonline.com.br/noticias/cidades/2018/02/triplica-o-numero-de-cotistas-nafederais-1014119250.html. Acesso em: 25 jun. 2019.

O GLOBO. Ministro da Educação garante que universidade pública seguirá gratuita. Rio de Janeiro, 28 de jan. de 2019. Sociedade. Disponível em https://oglobo.globo.com/sociedade/educacao/ministro-da-educacao-garante-queuniversidade-publica-seguira-gratuita-23407615. Acesso em: 28 jan. 2019.

OLIVEIRA, Dalila Andrade. As políticas educacionais no governo Lula: rupturas e permanências. Revista Brasileira de Política e Administração da Educação (RBPAE), v. 25, n.2, p. 197-209, mai./ago. 2009. Disponível em: https://seer.ufrgs.br/rbpae/article/view/19491. Acesso em: 12 ago. 2019.

PINA, Rute. Com R \$ 5,8 bilhões ainda congelados, situação de universidades permanece crítica. Brasil de Fato. São Paulo, 23 de maio de 2019. Disponível em: https://www.brasildefato.com.br/2019/05/23/com-rdollar-58-bilhoes-ainda-congeladossituacao-de-universidades-permanece-critical. Acesso em: 15 set. 2019.

RODRÍGUES, Margarita Victoria; ALMEIDA, Maria de Lourdes Pinto de. Políticas Educacionais e formação de professores em tempos de globalização. Brasília, DF: Editora UCDB, 2008.

ROMANELLI, Otaíza de Oliveira. História da Educação no Brasil (1930/1973). 25. ed. Petrópolis, RJ: Editora Vozes, 2001.

SILVA, Franklin Leopoldo e. Reflexões sobre o conceito e a função da universidade pública. Estudos Avançados, São Paulo, vol.15, n 42, mai./ago., 2001. Disponível em: http://www.scielo.br/scielo.php?script=sci_arttext\&pid=S0103-40142001000200015. Acesso em: 13 dez. 2018.

SOUZA, Antônia de Abreu et al. O Mundo do Trabalho e a Formação Crítica. Fortaleza: Edições UFC, 2012.

Recebido em: 15/10/2019

Aprovado em: 02/06/2020 